\title{
Microchip transponder thermometry for monitoring core body temperature of antelope during capture
}

Benjamin Rey ${ }^{1,2} *$, Andrea Fuller ${ }^{1}$, Robyn S Hetem ${ }^{1}$, Hilary M Lease ${ }^{1}$, Duncan Mitchell ${ }^{1}$ and Leith CR Meyer ${ }^{1,3}$

\footnotetext{
${ }^{1}$ Brain Function Research Group, School of Physiology, Faculty of Health Sciences, University of the Witwatersrand, 7 York Road, Parktown, Johannesburg 2193, South Africa.

${ }^{2}$ Present address : Laboratoire de Biométrie et Biologie Evolutive ; CNRS ; UMR 5558, Université Lyon 1, Université de Lyon, Villeurbanne, France.

${ }^{3}$ Department of Paraclinical Science, Faculty of Veterinary Science, Onderstepoort, University of Pretoria, South Africa
}

*Corresponding author. benjamin.rey@univ-lyon1.fr; Phone number: +33 4724329 29; Fax number: + 33472 431388

Author’s e-mail addresses: BR: benjamin.rey@univ-lyon1.fr ; AF: andrea.fuller@wits.ac.za; RH: robyn.hetem@wits.ac.za; HL: Hilary.lease@wits.ac.za; DM: duncan.mitchell@wits.ac.za; LM:

Leith.Meyer@up.ac.za

\section{Highlights}

- Abdominal, muscle and subcutaneous temperature was monitored using implanted loggers

- Capture and immobilization induces severe stress-induced hyperthermia in springboks

- Hyperthermia recovery was accelerated by artificial cooling

- Implanted subcutaneously, microchips poorly predict body temperature during capture

- Implanted intramuscularly, microchips poorly predict body temperature during capture

\begin{abstract}
Hyperthermia is described as the major cause of morbidity and mortality associated with capture, immobilization and restraint of wild animals. Therefore, accurately determining the
\end{abstract}


core body temperature of wild animals during capture is crucial for monitoring hyperthermia and the efficacy of cooling procedures. We investigated if microchip thermometry can accurately reflect core body temperature changes during capture and cooling interventions in the springbok (Antidorcas marsupialis), a medium-sized antelope. Subcutaneous temperature measured with a temperature-sensitive microchip was a weak predictor of core body temperature measured by temperature-sensitive data loggers in the abdominal cavity $\left(R^{2}=0.32\right.$, bias $\left.>2{ }^{\circ} \mathrm{C}\right)$. Temperature-sensitive microchips in the gluteus muscle, however, provided an accurate estimate of core body temperature $\left(R^{2}=0.76\right.$, bias $\left.=0.012{ }^{\circ} \mathrm{C}\right)$. Microchips inserted into muscle therefore provide a convenient and accurate method to measure body temperature continuously in captured antelope, allowing detection of hyperthermia and the efficacy of cooling procedures.

Keywords: hyperthermia; biologging; stress; ungulate; chemical immobilization

\section{Introduction}

Capture of wildlife for translocation, veterinary procedures, or research, which is crucial for wildlife conservation and management, induces severe hyperthermia in animals (Kock et al, 2006; Meyer et al., 2008). Capture-induced hyperthermia, which results primarily from stress or fear, and can be exacerbated by physical exertion (Meyer et al., 2010), is believed to be the predominant cause of morbidity and mortality when wildlife is captured (Williams \& Thorne 1996, Kock et al., 2006). To reduce the risk of mortality and improve the animals' welfare, captured animals that become hyperthermic often are cooled artificially by water-dousing (Sawicka et al., 2015). In current game-management practice, however, body temperature is not monitored continuously during capture or cooling, so neither the magnitude of the hyperthermia nor the effectiveness of the cooling is known during the event. 
If any index of core body temperature is measured during capture, it is usually rectal temperature, and it is generally measured only sporadically. However, when rapid changes in core body temperature occur, as is likely during capture and subsequent cooling, rectal temperature may lag behind core body temperature (Brengelmann 1987). Rectal temperature measurement also varies with probe position in the rectum, and requires placement for a few minutes to allow for probe temperature to stabilize (Mitchell and Laburn, 1985). Improving the ability to monitor core body temperature accurately and conveniently in wild animals during capture is essential for their well-being (Morkel et al., 2012; Ozeki et al., 2014).

Microchip thermometry has become a popular method for measuring an animal's thermal status for research purpose (Wacker et al. 2012) or clinical veterinary practice (Chen and White 2006; Lohse et al., 2010). To our knowledge, use of microchip thermometry never has been validated as a way of monitoring core body temperature during wildlife capture. We therefore simulated field capture of wild springbok (Antidorcas marsupialis) and investigated whether temperature measured with temperature-sensitive microchips reflects rapid changes in core body temperature (as reflected by abdominal temperature) associated with capture, chemical immobilization and artificial cooling. We inserted a microchip subcutaneously, because that remains the site usually employed in veterinary clinical practice. However, because subcutaneous temperature measured by microchips has been shown to predict core temperature poorly in domestic animals (see for example, Torrao et al., 2011), we also inserted a temperature-sensitive microchip into another easily accessible body region, a superficial muscle. We compared the microchip temperatures with abdominal temperatures recorded simultaneously with implanted temperature-sensitive data loggers. We also implanted miniature temperature-sensitive data loggers intramuscularly and subcutaneously to investigate how these peripheral temperatures varied compared to core body temperature during capture but also outside of capture periods, when springbok were undisturbed. We 
conclude that temperature-sensitive microchips can be used to measure body core temperature reliably during capture and subsequent cooling, but only if they are inserted into a muscle. Microchips implanted subcutaneously, standard positioning for identification microchips, were a poor surrogate for measuring core body temperature.

\section{Materials and methods}

All procedures were approved by the Animal Ethics Screening Committee of the University of the Witwatersrand (clearance certificate no. 2011-41-05).

\subsection{Animals}

Fourteen adult springbok (five males and nine females) weighing $23.6 \pm 3.4 \mathrm{~kg}$ (mean $\pm \mathrm{SD}$ ) were captured and held in a game-holding facility (Savanna Game Services cc) near Pretoria, South Africa. The springbok were housed in groups of two or three individuals in 7x10 m custom-built enclosures ("bomas"). The springbok received water, hay and lucerne (Medicago sativa) ad libitum, supplemented with concentrate pellets once a day. They were habituated to the enclosures for two weeks before surgical implantation of data loggers.

\subsection{Implantation of data loggers}

The surgical procedure for the implantation of data loggers was similar to that described previously for springbok (Hetem et al. 2009). Briefly, springbok were immobilised by intramuscular darts (dart gun plus $1.5 \mathrm{ml}$ darts with $30 \mathrm{~mm}$ length needle: Dan-Inject, Børkop, Denmark) each containing 0.8 mg etorphine hydrochloride (M99, Novartis, Johannesburg, South Africa) and $15 \mathrm{mg}$ azaperone (Stresnil, Janssen Pharmaceutica, Johannesburg, South Africa). At a nearby temporary theatre, they were intubated and surgical anaesthesia was maintained with 1-3\% isoflurane (Isofor, Safe Line, South Africa) in $100 \%$ medical oxygen. Implantation sites were shaved and disinfected with chlorhexidine gluconate. Before surgery, 
we infused local anaesthetic (5 ml lignocaine, subcutaneously (S.C.), Bayer, South Africa) at the implantation sites, and injected an anti-inflammatory agent $\left(0.25 \mathrm{mg} \cdot \mathrm{kg}^{-1}\right.$, meloxicam, I.M., Mobic, Ingelheim Pharmaceuticals Ltd, Randburg, South-Africa), a long-acting antibiotic (40 $\mu 1 . \mathrm{kg}^{-1}$, procaine benzylpenicillin, Duplocillin, I.M., Intervet, South Africa) and a broad-spectrum parasiticide (5 mg, doramectin, S.C., Dectomax, Pfizer Laboratories, Johannesburg, South Africa).

We inserted a temperature-sensitive data logger subcutaneously in the left paralumbar fossa (see details for temperature loggers below). At the same site, we accessed the peritoneal cavity through a laparatomy incision and inserted a logger intra-abdominally. We implanted a third data logger intramuscularly in the caudal thigh area between the semimembranosus and the semitendinosus muscles. Intramuscular loggers were tethered to the muscle using nonabsorbable sutures. At the end of surgery, the springbok were returned to their enclosure and the immobilizing effects of etorphine were reversed with intravenous diprenorphine hydrochloride (4 mg, M5050, Novartis, South Africa). Healing of the surgical incisions and general animal health were monitored by veterinary staff on a daily basis. At the end of the study, we followed similar surgical procedures to remove the data loggers.

\subsection{Simulation of capture and immobilization, and insertion of microchips}

Eight weeks after logger implantation, we simulated capture and immobilization. Captures were carried out between 09:00 and 18:00. All springbok from an enclosure (two or three animals) were herded via a corridor into a capture enclosure, where they were captured by hand within 2 minutes by experienced handlers of wild ungulates, moved to a larger enclosure nearby and restrained manually on their sides. The springbok were blindfolded and cottonwool earplugs were placed in their external auditory canals. Ten minutes (mean \pm SD: $10 \pm 1$ min) from initial herding, we injected each springbok with $0.7 \mathrm{mg}$ etorphine hydrochloride 
and $10 \mathrm{mg}$ azaperone intramuscularly. Once immobilized, the springbok were positioned in sternal recumbency, and we inserted the temperature-sensitive microchips (see below) by percutaneous injection. One microchip was inserted subcutaneously between the shoulder blades and another microchip into the gluteal muscle.

For each group of springbok from an enclosure, at least one animal (but never all) was subjected to cooling by dousing with water, starting half an hour after initial herding (mean \pm $\mathrm{SD}: 29 \pm 3 \mathrm{~min})$. In one group $(\mathrm{n}=7$, three males, four females, $23.5 \pm 3.1 \mathrm{~kg})$, water at ambient temperature (range: $25-31^{\circ} \mathrm{C}$ ) was doused and spread by hand on the back and flanks of the springbok over a 6 min interval. After 6 min, another 41 of water was applied in the same manner. The remaining animals in the group were not cooled with water and were referred to as "non-doused" ( $\mathrm{n}=7$, two males, five females, $23.7 \pm 3.0 \mathrm{~kg}$ ). At the end of the procedure, we returned the springbok to their original enclosure and reversed the effects of etorphine hydrochloride with $4 \mathrm{mg}$ diprenorphine hydrochloride. The duration of the whole procedure (from initial herding to drug reversal) was $56 \pm 4$ min.

\subsection{Climatic variables}

We recorded climatic variables on site at 30 min intervals using a portable weather station (Hobo U30-NRC Data Logger, C.W.Price \& Co, Midrand, South Africa). During the captures, minimum and maximum air temperature varied from $20^{\circ} \mathrm{C}$ to $28^{\circ} \mathrm{C}$ (mean $\pm \mathrm{SD}: 24$ $\pm 2{ }^{\circ} \mathrm{C}$ ), black globe temperature (integrated measure of air temperature, solar radiation and wind speed and used as an index of heat load; Kuehn et al. 1970) varied from $29^{\circ} \mathrm{C}$ to $49^{\circ} \mathrm{C}$ (mean \pm SD: $41 \pm 5^{\circ} \mathrm{C}$ ), and relative humidity varied from $48 \%$ to $65 \%$ (mean \pm SD: $57 \pm 6$ $\%)$. Immobilized springbok were maintained in the shade for microchip temperature readings. Outside of capture periods, the springbok had free access to shade. 


\subsection{Data loggers and microchips}

We used temperature-sensitive data loggers to record abdominal (StowAway XTI, Onset Computer Corporation, Pocasset, USA, resolution $0.04{ }^{\circ} \mathrm{C}$, mass $40 \mathrm{~g}$ ), muscle (DS1922L Thermochron iButtons, Dallas Semiconductor, USA; resolution $0.0625^{\circ} \mathrm{C}$, mass $5 \mathrm{~g}$ ) and subcutaneous (ADXL345, Sigma Delta Technologies, Perth, Australia; resolution $0.06{ }^{\circ} \mathrm{C}$, mass $20 \mathrm{~g}$ ) temperatures at five-minute intervals. The loggers were encased in inert wax (Sasol, Johannesburg, South Africa) and dry-sterilised in formaldehyde vapour.

The thermal time constant (90\% response to a step change in temperature) of our temperature loggers ranged from 15 to 20 s (when they were immersed in stirred water) according to the manufacturer's instructions and previously published data (van Marken Lichtenbelt et al. 2006). The microchips that we used were temperature-sensitive transponders (Bio Thermo microchip, Identipet Ltd, Muldersdrift, South Africa; resolution $0.1{ }^{\circ} \mathrm{C}$, mass $0.06 \mathrm{~g}, 12 \mathrm{~mm}$ length $\times 2.1 \mathrm{~mm}$ diameter). They also were dry-sterilised in formaldehyde vapour, and their output signals monitored with a portable scanner (Bio Thermo Pocket reader, Identipet). Before the loggers and microchips were implanted, we calibrated them in a circulating water bath against a high-accuracy thermometer (Quat 100, Heraeus, Germany) to an accuracy better than $0.1{ }^{\circ} \mathrm{C}$ as previously described (Torrao et al. 2011).

\subsection{Statistical analyses}

We used a non-parametric Mann-Whitney U-test to analyze differences in abdominal temperatures between doused and non-doused springbok (area under the curve). Comparison of logger temperatures recorded at the different body sites before and after herding and immobilization was tested using paired t-tests. The agreement between abdominal temperature and the temperatures measured with microchips was estimated using the limit of agreement methods for repeated paired measurements (Bland \& Altman 2007). For each 
microchip location, limits of agreement were calculated using 42 paired measurements from 14 individuals.

We next fitted mixed-effect linear models to describe the relationship between abdominal temperatures and temperatures measured at different sites with microchips, and to test for the effect of water-dousing on these relationships. Abdominal temperature $\left(\mathrm{T}_{\mathrm{abdomen}}\right)$ was used as a dependent variable with temperatures measured by the microchip (subcutaneous: $\mathrm{T}_{\text {subcutaneous }}$ or muscle temperature: $\mathrm{T}_{\text {muscle }}$ ) as explanatory variables. We entered a categorical variable "group" with two modalities ("doused" and "non-doused") and tested for the interaction between the temperature measured with each microchip ( $\left.\mathrm{T}_{\text {microchip }}\right)$ and "group". We entered a variable "individuals" (ID) as a random factor, to take into account pseudoreplication

resulting from multiple measurements per animal. The overall model was: $\mathrm{T}_{\text {abdomen }} \sim \mathrm{T}_{\text {microchip }}$ + group $+\mathrm{T}_{\text {microchip }} \mathrm{x}$ group $+\mathrm{ID}_{\text {[random] }}$.

The pattern of body temperatures (Figure 4) were averaged over three consecutive days prior to capture trials in nine springboks in which abdominal, muscle and subcutaneous temperatures were all successfully recorded. We performed statistical analyses with $\mathrm{R}$ software environment (http://cran.at.r-project.org) using functions 'lme'. $\mathrm{P}<0.05$ was considered significant. Unless specified, values are given as mean $\pm \mathrm{SD}$.

\section{Results}

The profiles of abdomen, muscle and subcutaneous temperatures recorded with data loggers in the springbok before, during and after the simulated capture and immobilization, with (panel B) and without (panel A) water-dousing, are presented in Figure 1. In both groups, initial disturbance and herding of the springbok resulted in a rise of abdominal temperature at a rate of $\sim 0.1^{\circ} \mathrm{C} \cdot \mathrm{min}^{-1}$. That rate had started to decrease by the time that the springbok were captured by hand, and attenuated further after they were immobilized chemically. At the time 


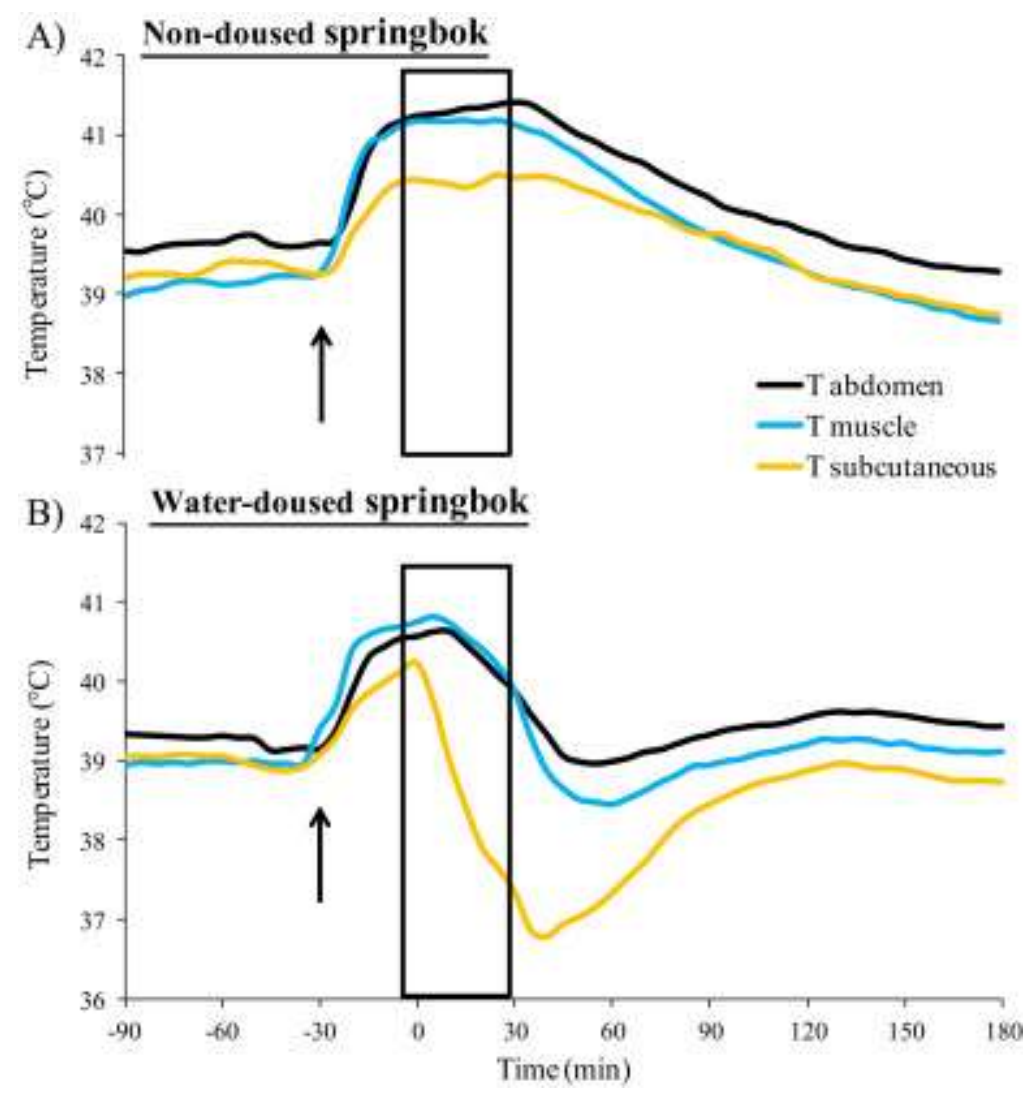

Figure 1: Time course of changes in abdominal, muscle and subcutaneous temperatures concurrently measured at five minute intervals by implanted temperature-sensitive data loggers before, during and after simulated capture and chemical immobilization of non-doused (panel A, n= 5) and water-doused springbok $($ panel B, n= 4). The black arrow indicates when the springbok were first herded prior to capture. The black rectangles represents the period of chemical immobilization ( $0.8 \mathrm{mg}$ etorphine, $15 \mathrm{mg}$ azaperone). Water dousing started at time 0 and consisted of two 41 dousing sessions of 6 min each, separated by a 6 min rest period. For clarity, bar errors are not shown (see the Result section for statistical analyses).

at which water-dousing was started, abdominal temperature had risen by $1.54 \pm 0.42{ }^{\circ} \mathrm{C}$ $(\mathrm{n}=14)$. The abdominal temperatures of the non-doused springbok continued to rise, and peaked at $41.47 \pm 0.30{ }^{\circ} \mathrm{C}(\mathrm{n}=7)$ by the time that chemical immobilization was reversed. In those springbok, abdominal temperature then fell gradually, initially at about $0.02{ }^{\circ} \mathrm{C} \cdot \mathrm{min}^{-1}$, and continued to fall for at least $150 \mathrm{~min}$. In springbok doused with water, initial application of water (4 1 in $6 \mathrm{~min}$ ) did not immediately arrest the rate of rise of abdominal temperature. After the second dousing, however, the abdominal temperature fell almost as fast as it had 
risen initially, overshooting the temperature prevailing before herding, and then returning gradually to reach the same temperature as that of non-doused springbok about two hours after the initial dousing. The total integrated change in abdominal temperature (area under the curve from the start of herding till $3 \mathrm{~h}$ later) was significantly greater (Mann-Whitney U-test results: $\mathrm{p}=0.04)$ for non-doused springbok $\left(139 \pm 27^{\circ} \mathrm{C} . \mathrm{h}\right)$ than for doused springbok $(51 \pm$ $35^{\circ}$ C.h).

We observed the same general pattern of temperature changes in muscles of the caudal thigh area. However, muscle temperature recorded 90 min before capture was $0.5 \pm 0.1^{\circ} \mathrm{C}$ lower than that measured in the abdomen; this difference was statistically significant (paired t-test, $\mathrm{p}<0.001, \mathrm{n}=9$ ). These muscle temperatures, measured $2 \mathrm{~h}$ after release, were also significantly lower than that measured in the abdomen (paired t-test, $0.5 \pm 0.3^{\circ} \mathrm{C} ; \mathrm{p}<0.01, \mathrm{n}=9$ ). During the whole capture and immobilization process, the muscle temperature was similar to abdominal temperature and the maximal recorded temperatures did not vary significantly between these two sites (paired t-test, $\mathrm{p}=0.6, \mathrm{n}=9$ ). Subcutaneous logger temperature followed the same general pattern, but was consistently lower than abdominal temperature before, during and after the capture and immobilization process.

Figure 2 illustrates, at a finer scale, changes in abdominal (data logger), gluteal muscle (microchip) and subcutaneous (microchip) temperatures during chemical immobilization. In non-doused springbok, abdominal temperature rose gradually, while gluteal muscle temperature fell gradually during immobilization. In doused springbok, the initial gluteal muscle and abdominal temperature profile was similar to the non-doused group until the time of dousing when both temperatures fell. In both non-doused and doused springbok, abdominal temperature and gluteal muscle temperature never differed by more than a few tenths of a degree of each other. Subcutaneous temperature, on the other hand, consistently was lower than abdominal temperature and gluteal muscle temperature. Water-dousing increased the 
difference between abdominal and subcutaneous temperature, with subcutaneous temperature more than $2{ }^{\circ} \mathrm{C}$ lower than abdominal temperature on average.
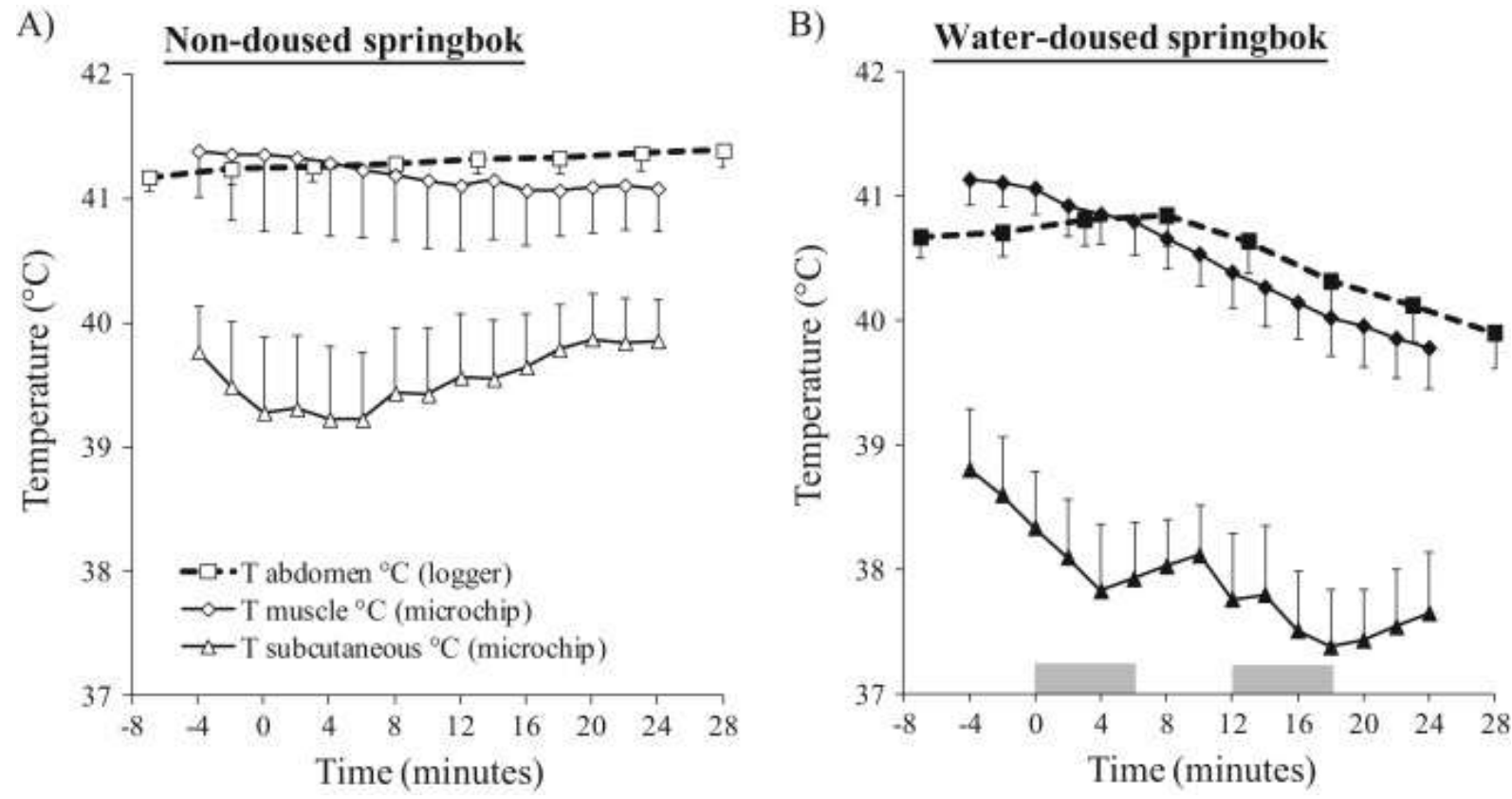

Figure 2: Abdominal (squares), gluteal muscle (diamonds) and interscapular subcutaneous (triangles) temperatures measured in non-doused (open symbol, panel A, $\mathrm{n}=7$ ) and water-doused (closed symbol, panel B, $\mathrm{n}=7$ ) springbok during simulated capture and immobilization. The springbok were herded, captured by hand and immobilized ( $0.8 \mathrm{mg}$ etorphine, $15 \mathrm{mg}$ azaperone), after which the microchips were inserted. Water-doused springbok had 41 of water at ambient temperature (range: $25-31^{\circ} \mathrm{C}$ ) spread over their backs and flanks over two 6 min sessions (grey bars). Abdominal temperature was measured with implanted temperature-sensitive data loggers and muscle and subcutaneous temperatures were measured with temperature-sensitive microchips. Water dousing (dark bars) started at time 0 and consisted of two 41 dousing sessions of 6 min each, separated by a 6 min rest period. Data are expressed as mean \pm sem.

Consistent with the temperature patterns in Figure 2, a Bland-Altman plot (Figure 3) shows that the interscapular subcutaneous microchip temperature exhibited a large bias with high variability (bias: $2.12^{\circ} \mathrm{C}$, limit of agreement: -0.41 to $4.66^{\circ} \mathrm{C}$; Fig $3 \mathrm{~A}$ ) when compared to simultaneous abdominal logger temperatures. Nevertheless, there was a significant linear association between abdominal logger temperature and subcutaneous microchip temperature 

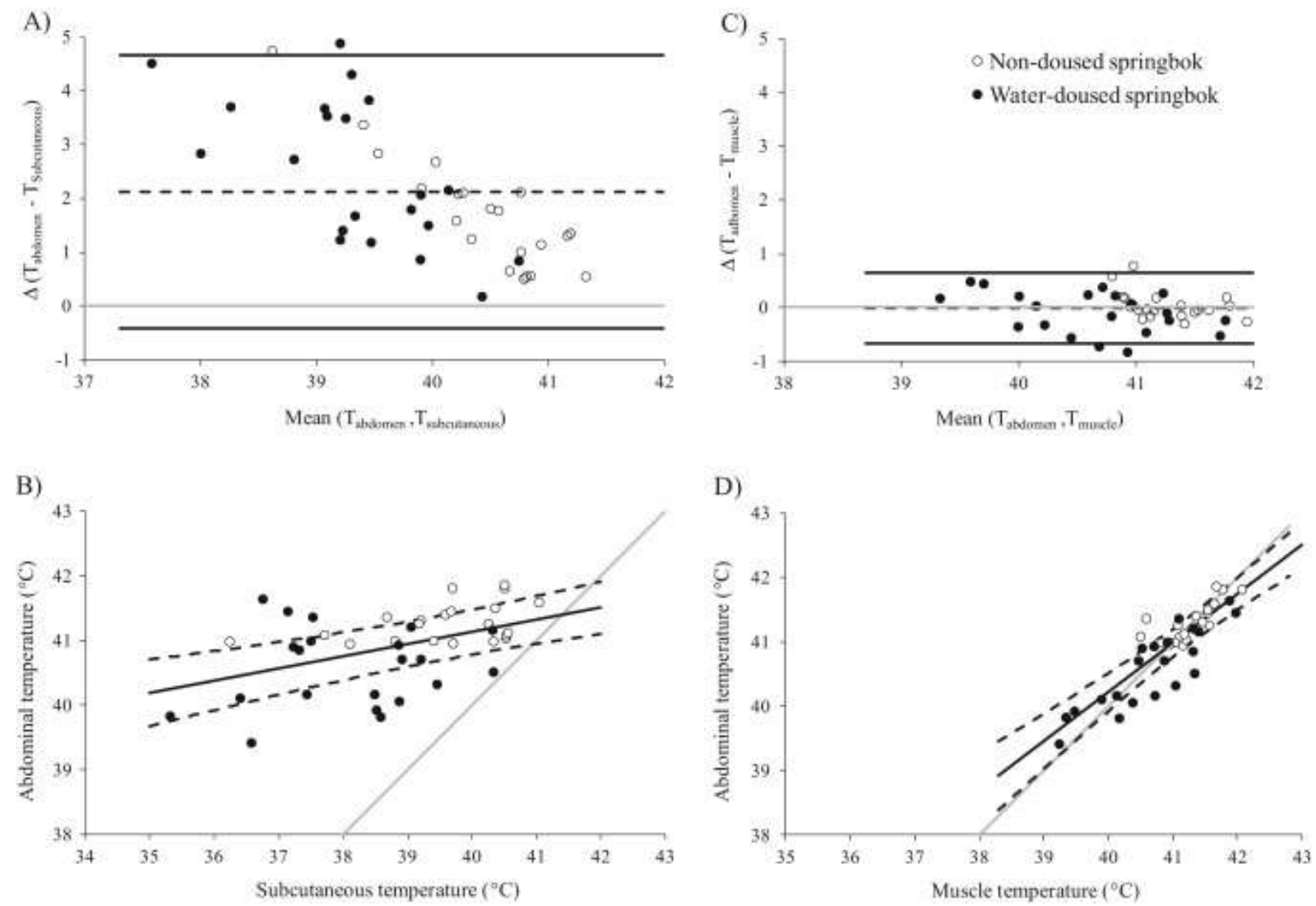

Figure 3: Comparison of abdominal temperature and interscapular subcutaneous temperature (A, B), and abdominal temperature and gluteal muscle temperature $(\mathrm{C}, \mathrm{D})$, during simulated capture and immobilization of springbok, with (closed symbol) and without (open symbol) the water-dousing cooling procedure (See Fig 1 for details). Abdominal temperature was measured with implanted temperature-sensitive data loggers and muscle and subcutaneous temperatures were measured with temperature-sensitive microchips.

Upper panels: Bland-Altman plot of the difference between abdominal and subcutaneous (A) or muscle (C) temperatures vs. means of the compared temperatures. The grey lines represent no difference between abdominal temperature and subcutaneous or muscle temperatures. The black lines represent the bias (mean difference between compared temperatures). The black dashed lines represent the upper and the lower limits of agreement. Lower panels: Relationships between abdominal temperature and subcutaneous (B) or muscle (D) temperatures. The black lines are the best-fit linear regressions, and the dashed lines their $95 \%$ prediction limits. The grey lines are the lines of identity $(\mathrm{x}=\mathrm{y})$.

during immobilization ( $\mathrm{F}=8.33$; $\mathrm{p}<0.007)$. The slope of the relationship was not significantly different between doused and non-doused springbok $(\mathrm{F}=3.34 ; \mathrm{p}=0.093)$ and there was no interaction between the variable " $\mathrm{T}_{\text {subcutaneous" }}$ and the variable "group" $(\mathrm{F}=0.95 ; \mathrm{p}=0.34)$. In 
other words, the relationship between abdominal temperature and subcutaneous temperature was not altered by the cooling procedure. The linear relationship between abdominal and interscapular subcutaneous temperature was: $\mathrm{T}_{\text {abdomen }}=0.19 \times \mathrm{T}_{\text {subcutaneous }}+33.6 ; \mathrm{R}^{2}=0.31$ (Fig. 3B).

With a bias of $-0.012^{\circ} \mathrm{C}$ and with little variability (limit of agreement: -0.67 to 0.64 ${ }^{\circ} \mathrm{C}$ ), gluteal muscle microchip temperature was similar to abdominal logger temperature (Fig 3C). Gluteal muscle temperature also was significantly associated linearly with abdominal temperature $(\mathrm{F}=39.27 ; \mathrm{p}<0.001)$, with the regression line closer to the line of identity $\left(\mathrm{T}_{\mathrm{abdomen}}=0.76 \times \mathrm{T}_{\text {muscle }}+9.66 ; \mathrm{R}^{2}=0.76\right)$ than for subcutaneous and abdominal temperature. Dousing also did not significantly affect this relationship $(\mathrm{F}=4.69, \mathrm{p}=0.061)$ and there was no significant interaction between the variables " $\mathrm{T}_{\text {muscle" }}$ and the variable "group" $(\mathrm{F}=1.74$, $\mathrm{p}=0.19)$.

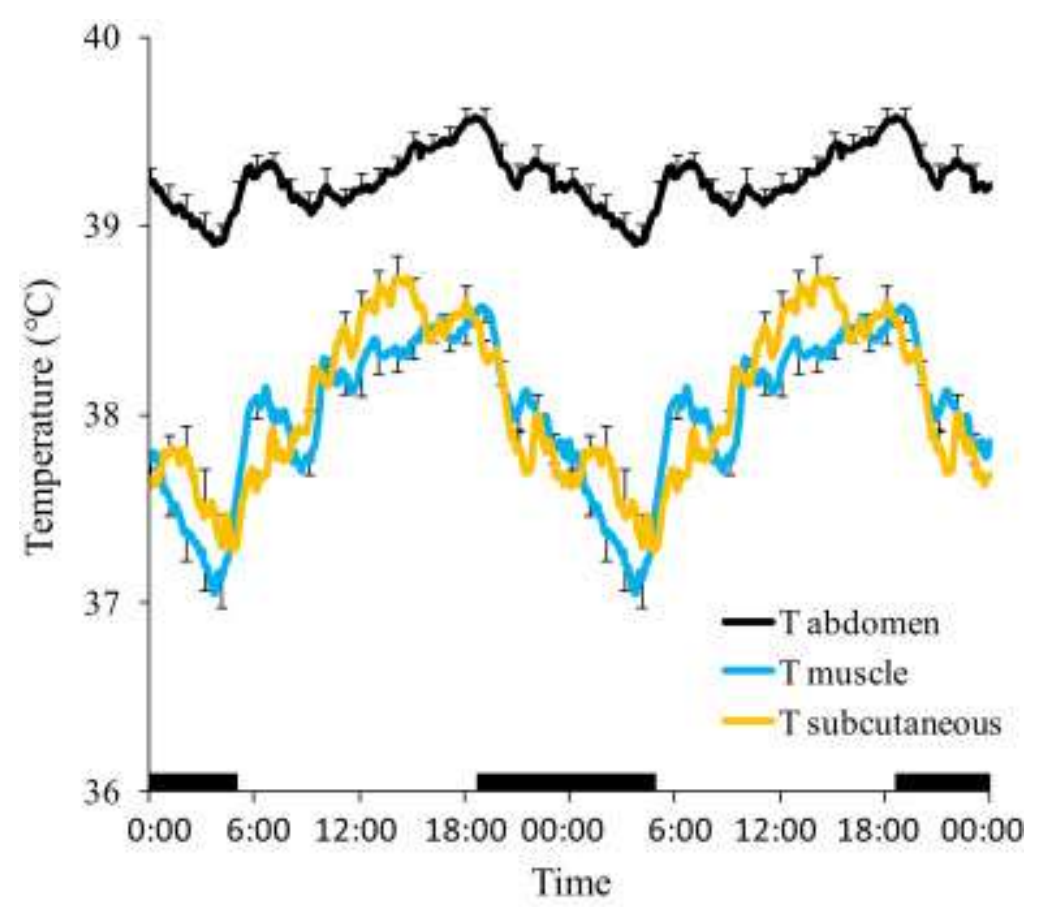

Figure 4: Double plots of $24 \mathrm{~h}$ rhythms (mean \pm sem) of abdominal temperature (black line), muscle temperature recorded in the caudal thigh area (dark grey line) and subcutaneous temperature recorded in the left paralumbar fossa (light grey line) in nine wild-caught springbok in holding enclosures (bomas) during a period of no interventions. Dark bars indicate night. 
Figure 4 shows the $24 \mathrm{~h}$ pattern of abdominal, muscle and subcutaneous temperatures, measured by implanted data loggers, in undisturbed springbok. At all three body regions, the temperature showed nychthemeral fluctuations with troughs just before sunrise and peaks around sunset. In these undisturbed springbok, temperature recorded in muscles of the caudal thigh area and subcutaneous temperatures were much closer to each other than either was to abdominal temperature, and they differed from abdominal temperature inconsistently by up to $2{ }^{\circ} \mathrm{C}$. The peak-to-trough amplitudes of the $24 \mathrm{~h}$ rhythms of muscle logger temperature $(1.91 \pm$ $\left.0.28{ }^{\circ} \mathrm{C}\right)$ and subcutaneous logger temperature $\left(1.9 \pm 0.4{ }^{\circ} \mathrm{C}\right)$ were much greater than that of abdominal temperature $\left(0.9 \pm 0.3^{\circ} \mathrm{C}\right)$.

\section{Discussion}

We have shown, in springbok hand captured and chemically immobilized, that gluteal muscle measured by temperature-sensitive microchips provides a suitable surrogate temperature for abdominal temperature. Gluteal muscle temperature was similar to abdominal temperature during the hyperthermia associated with capture, and it decreased with abdominal temperature when the animals were cooled by water-dousing. The average difference (bias) between gluteal muscle and abdominal temperatures during capture was small $\left(0.012{ }^{\circ} \mathrm{C}\right)$. In contrast, interscapular subcutaneous temperature measured by microchips was substantially lower than was abdominal temperature $\left(2.13^{\circ} \mathrm{C}\right)$, with this difference increasing at low body temperatures (Fig. 3B).

The body temperature profiles exhibited by the springbok in our simulated capture and immobilization mirrored those measured in captured wild antelope previously. Our capture procedure resulted in a rapid increase in springbok abdominal temperature, of almost $2{ }^{\circ} \mathrm{C}$ (Fig. 1), followed by a slow resolution of the hyperthermia to normothermy, a pattern similar to that seen when springbok were captured from the wild (Fuller et al., 2005). The precipitous 
rise in abdominal temperature of our springbok also was similar to that observed during capture and immobilization of other medium-sized African antelope such as impala (Aepyceros melampus; Meyer et al., 2008) and blesbok (Damaliscus dorcas; Sawicka et al., 2015). Water dousing rapidly and effectively decreased abdominal temperature (Fig. 1 and 2) of the springbok, as it did in hyperthermic blesbok (Sawicka et al., 2015). We thus believe that our simulation mimicked capture of wild-caught antelope, and provides a suitable platform for us to explore the utility of temperature measurement with microchips.

A stress-induced hyperthermia in wild antelope is characteristic of most captures, and could be detected accurately and easily with microchips placed percutaneously into the gluteus muscle. It is reasonable to expect that intramuscular microchips are suitable for monitoring changes in body temperature during capture procedures in other African antelope such as impala or blesbok for which body composition (van Zyl et al. 2004) as well as the thermal response to capture are similar to that of springbok (add references - my impala work and Marna Broekman's dissertation). Whether muscle temperatures measured with microchips are appropriate for accurately monitoring capture-induced hyperthermia in other mammals, especially larger species, remains to be confirmed. Gluteal muscle temperature has been shown to be suitable for monitoring body temperature during capture and immobilization in black rhino (Morkel et al. 2012). Therefore, intramuscularly implanted microchips should be effective for this purpose in rhinoceros.

However, it should be noted that, at times other than capture, when animals were undisturbed, muscle temperature, as measured continuously by data loggers implanted in the caudal thigh area, was much lower than abdominal temperature (Fig. 1 and 4). The difference between abdominal and muscle temperature varied over the course of a $24 \mathrm{~h}$ day, and was greatest around sunrise, when springbok body temperatures were lowest and muscle blood flow likely was low (Fig 4). During capture, the tight relationship between muscle temperature measured 
either with data loggers (Fig. 1) or microchips (Fig. 2 \& 3) and abdominal temperature probably result from the increase in blood flow to active skeletal muscles associated with metabolic dilatation of muscle blood vessels occurring during exercise and a flight-or-flight response. Although muscle temperature therefore may be a surrogate for abdominal temperature during capture (and perhaps other events in which muscle blood flow is high), subcutaneous temperature measured with a temperature logger (Fig $1 \& 4$ ) or by implanted microchips (Fig. 3) provided a poor indication of abdominal temperature at all times. During capture and immobilization, interscapular subcutaneous temperatures were as much as $5{ }^{\circ} \mathrm{C}$ lower than abdominal temperatures (Fig. 3A). Measurement of subcutaneous temperature on its own could lead to the erroneous conclusion that captured antelope were not hyperthermic, resulting in necessary cooling interventions not being implemented. The lack of agreement between abdominal and subcutaneous temperatures also was evident in undisturbed springbok in their enclosures (Fig. 4B), and is consistent with previous observations in medium-sized and large companion and production mammals. Indeed, in dogs, goats, sheep and horses, subcutaneous temperatures measured by microchip thermometry do not accurately reflect core body temperatures (Goodwin et al., 1998; Torrao et al., 2011). In contrast, in several smaller mammals, including marmosets (Cilia et al., 1998), rodents (Kort et al., 1998), rabbits (Chen and White, 2006) and cats (Quimby et al., 2009), subcutaneous temperatures measured by temperature-sensitive microchips agree acceptably with rectal temperatures; subcutaneous temperature agreement with abdominal temperature, however, has not yet been explored in these animal models.

Because wild animals are now often implanted with microchips for identification purposes, and because microchips are easy to insert, even in muscles, microchip thermometry is an attractive tool for measuring core body temperature during capture procedures. Although we inserted microchips into springbok while they were immobilized, animals are not 
immobilized, conventionally, when microchips are inserted subcutaneously for identification purposes. We propose that microchips could be inserted into the muscles of conscious animals, particularly if they were limited in movement by small enclosures or transport vehicles, with a device similar to a pole syringe. Whether microchips, so inserted, would stay in the muscle over time needs to be investigated and is a potential limitation of such a technique. Furthermore, whether a microchip scanner can be placed on a pole to read a microchip's output signal at a safe distance from a conscious animal also needs to be determined. We did not detect any swelling or pain responses in the springbok following insertion of the microchips. However, despite microchips being covered by biocompatible material which should not evoke a tissue response, microchips inserted subcutaneously have been reported to induce moderate yet measurable transient inflammation, swelling and hyperalgesia at their insertion site (Gerber et al., 2012). Another potential limitation associated with long-term use is an increased risk of neoplasia and tumor formation surrounding subcutaneous microchips (Elcock et al. 2001). Such effects are currently not known for intramuscular insertion and warrant further investigations.

\section{Conclusion}

Temperature-sensitive microchips inserted subcutaneously do not reflect core body temperatures of captured and immobilized springbok accurately. In contrast, microchips implanted in the gluteus muscle accurately reflect core body temperature during simulated capture and immobilization. We believe that such temperature-sensitive microchips could be quickly and easily inserted in conscious animals constituting an attractive alternative tool for monitoring capture-induced hyperthermia. Our findings reveal that microchips hold promise for monitoring the hyperthermia induced by capture and immobilization, and for assessing the 
effectiveness of cooling interventions, potentially decreasing the morbidity and mortality of captured wildlife.

\section{Acknowledgments}

We are very grateful to Mary-Ann Costello, Anna Haw, Chris Kingsley and staff of Savanna Game Services for their valuable assistance. We thank the Claude Leon Foundation, the South African National Research Foundation and the University of the Witwatersrand for financial support.

\section{References}

Bland, J. M., Altman, D. G., 2007. Agreement between methods of measurement with multiple observations per individual. J Biopharm Stat. 17, 571-582.

Brengelmann, G. L., 1987. Dilemma of body temperature measurement. In: Shiraki K, Yousef MK, editors. Man in stressful environments: thermal and work physiology. Springfield (IL): Charles C. Thomas, pp 5-22

Chen, P. H., White, C. E., 2006. Comparison of rectal, microchip transponder, and infrared thermometry techniques for obtaining body temperature in the laboratory rabbit (Oryctolagus cuniculus). J Am Assoc Lab Anim Sci. 45, 57-63.

Cilia, J., Piper, D. C., Upton, N., Hagan, J. J., 1998. A comparison of rectal and subcutaneous body temperature measurement in the common marmoset. J Pharmacol Toxicol Methods. 40, 21-26. Elcock, L. E., Stuart, B. P., Wahle, B. S., Hoss, H. E., Crabb, K., Millard, D. M., Mueller, R.E., Hastings, T.F., Lake, S. G., 2001. Tumors in long-term rat studies associated with microchip animal identification devices. Exp Toxicol Pathol. 52, 483-491.

Fuller, A., Kamerman, P.R., Maloney, S.K., Matthee, A., Mitchell, G., Mitchell, D., 2005. A year in a thermal like of a free-ranging herd of springbok Antidorcas marsupialis. J Exp Biol. 208, 2855-2844. Gerber, M. I., Swinker, A. M., Staniar, W. B., Werner, J. R., Jedrzejewski, E. A., Macrina, A. L., 2012. Health factors associated with microchip insertion in horses. J Equine Vet Sci. 32, 177-182. 
Goodwin, S. D., 1998. Comparison of body temperatures of goats, horses, and sheep measured with a tympanic infrared thermometer, an implantable microchip transponder, and a rectal thermometer. $\mathbf{J}$ Am Assoc Lab Anim Sci. 37, 51-55.

Hetem, R. S., de Witt, B. A., Fick, L. G., Fuller, A., Kerley, G. I., Meyer, L. C., Mitchell, D., Maloney, S. K., 2009. Body temperature, thermoregulatory behaviour and pelt characteristics of three colour morphs of springboks Antidorcas marsupialis. Comp Biochem Physiol part A: Mol Integr Physiol. 152, 379-388.

Kort, W. J., Hekking-Weijma, J. M., TenKate, M. T., Sorm, V., VanStrik, R., 1998. A microchip implant system as a method to determine body temperature of terminally ill rats and mice. Lab Anim. $32,260-269$.

Kock, M., Meltzer, D., Burroughs, R., 2006. Chemical and physical restraint of wild animals; a training and field mammal for African species. International Wildlife Veterinary Services (Africa), Greyton, South Africa, 292 pp.

Kuehn, L. A., Stubbs, R. A., Weaver, R. S., 1970. Theory of the globe thermometer. J Appl Physiol. $29,750-757$.

Lohse, L., Uttenthal, Å., Enøe, C., Nielsen, J., 2010. A study on the applicability of implantable microchip transponders for body temperature measurements in pigs.

Acta Vet Scand 52:1-29

Meyer, L. C. R., Fick, L. G., Matthee, A., Mitchell, D., Fuller, A., 2008. Hyperthermia in captured impala (Aepyceros melampus): a fright not flight response. J Wildl Dis. 44, 404-416.

Meyer, L. C. R., Hetem, R. S., Fick, L. G., Mitchell, D., Fuller, A., 2010. Effects of serotonin agonists and doxapram on respiratory depression and hypoxemia in etorphine-immobilized impala (Aepyceros melampus). J Wildl Dis. 46, 514-524.

Mitchell, D., Laburn, H. P., 1985. Pathophysiology of temperature regulation. Physiologist. 28, 507517.

Morkel, P. V., Miller, M., Jago, M., Radcliffe, R. W., Du Preez, P., Olea-Popelka, F., Sefton J., Taft A., Nydam D., Gleed, R. D., 2012. Serial temperature monitoring and comparison of rectal and muscle 
temperatures in immobilized free-ranging black rhinoceros (Diceros bicornis). J Zoo Wildl Med. 43, $120-124$.

Ozeki, L. M., Fahlman, Å., Stenhouse, G., Arnemo, J. M., Caulkett, N., 2014. Evaluation of the accuracy of different methods of monitoring body temperature in anesthetized brown bears (Ursus arctos). J Zoo Wildl Med. 45, 819-824.

Quimby, J. M., Olea-Popelka, F., Lappin, M. R., 2009. Comparison of digital rectal and microchip transponder thermometry in cats. J Am Assoc Lab Anim Sci. 48, 402.

Sawicka, J., Fuller, A., Fick, L. G., Hetem, R. S., Meyer, L. C. R., 2015. Efficacy of different cooling methods for capture-induced hyperthermia in antelope. S Afr J Wildl Res. 45, 100-110.

Torrao, N. A., Hetem, R. S., Meyer, L. C. R., Fick, L. G., 2011. Assessment of the use of temperaturesensitive microchips to determine core body temperature in goats. Vet Rec. 168, 328-328.

van Zyl, L., and Ferreira, A. V., 2004. Physical and chemical carcass composition of springbok (Antidorcas marsupialis), blesbok (Damaliscus dorcas phillipsi) and impala (Aepyceros melampus). Small Rumin Res. 53, 103-109.

Wacker, C. B., Rojas, A. D., and Geiser, F. (2012). The use of small subcutaneous transponders for quantifying thermal biology and torpor in small mammals. J Therm Biol. 37, 250-254.

Williams, E., Thorne, E., 1996. Exertional myopathy (capture myopathy) in Fairbrother, A., Locke, L.N., Hoff, G.L. (Eds). Non-infectious diseases of wildlife. Iowa State University Press, Ames, Iowa, pp 181-193. 